\title{
Das (im) possibilidades de avaliar a leitura literária na escola: um estudo de caso
}

\author{
Of the (im) possibilities of evaluating literary reading in school: a study case
}

Raquel Cristina de Souza e Souza

Colégio Pedro II - Realengo - Rio de Janeiro - Brasil

Resumo: O trabalho com o texto literário nos anos finais do ensino fundamental ainda carece de fundamentação teórico-metodológica clara - inclusive nos documentos oficiais - para balizar uma prática docente efetivamente produtiva no que tange à formação de leitores. Emparedado entre duas lógicas distintas de abordagem do texto literário, o EFII parece ficar à deriva entre a perspectiva da leitura como participação, segundo a qual a promoção da leitura se sobreleva ao texto, e a leitura como distanciamento, cuja ênfase formalista não raro rechaça a subjetividade leitora. Este trabalho pretende, então, a partir de um estudo de caso, apresentar uma alternativa de conciliação entre as duas perspectivas a partir do uso de instrumentos pedagógicos de registro da recepção subjetiva de textos literários: diário de leitura, autobiografia de leitor e correspondência literária. Acompanharemos o percurso de um aluno repetente do sexto ano do ensino fundamental ao longo de 2016 e 2017 por meio de seus testemunhos de leitor para mostrar como o investimento subjetivo no processamento da leitura torna possível não só o desenvolvimento de competências leitoras como o envolvimento afetivo com o ato de ler.

Palavras-chave: Recepção. Leitura subjetiva. Anos finais do ensino fundamental.

Abstract:: The work with the literary text in Middle Scholl still lacks clear theoretical and methodological foundation - which includes the official documents - in order to ground an effectivelly productive teaching practice regarding readers' development. Compressed between two distinct approaches to dealing with the literary text, Middle Scholl teachers seem to drift between the perspective of reading as participation, whereby reading promotion overcomes the text, and reading as distancing, whose formalistic emphasis often rejects subjectivity. This paper intends, based on a case study, to present a conciliation alternative between the two perspectives by using different pedagogical tools to record the subjective reception of literary texts: reading journal, reader autobiography and literary correspondence. We will follow the course of a retained sixth grade student through 2016 and 2017 registered on his reader testimonies to show how subjective investment in reading processing makes it possible not only to develop reading skills but also an affective engagement with the act of reading.

Keywords: Reception. Subjective reading. Middle School. 


\section{Introdução}

Pensar a leitura literária no contexto dos anos finais do ensino fundamental significa ter de enfrentar realidades muito díspares em relação à abordagem do texto em sala de aula. Talvez isso se deva às próprias características desta etapa de ensino, emparedada entre os anos inicias e o ensino médio e, consequentemente, entre dois acercamentos distintos ao literário: a leitura participação (DELBRASSINE, 2007), que justifica a ênfase nas estratégias de aproximação e promoção da leitura, expressão pessoal, estímulo ao imaginário e identificação; e a leitura distanciamento (DELBRASSINE, 2007), que prevê a mobilização de recursos complexos de compreensão e interpretação muitas vezes redundando em uma prática descarnada e asséptica de leitura.

Tal dicotomia se reflete em duas posturas tão recorrentes quanto antagônicas que podem ser verificadas no trabalho com o texto literário do sexto ao nono ano. Por um lado, instrumentalizados pela voga das teorias enunciativas nos documentos oficiais (como os Parâmetros Curriculares Nacionais) e nos cursos universitários de formação docente, alguns professores acabam por não distinguir o domínio literário de outros domínios discursivos, tornando o trabalho com o texto literário um exercício formalista e limitado em suas potencialidades simbólicas e subjetivas. Por outro lado, no campo dos estudos literários, a escassez de reflexões teóricometodológicas sobre a abordagem do literário nesta etapa de ensino (que caminha de par a par com o desprestígio da literatura juvenil nas universidades) abre espaço para um discurso problemático sobre o prazer de ler que embaça questões de extrema relevância acerca da responsabilidade da escola na formação de leitores.

O que significa, afinal, advogar pelo prazer de ler na escola? Muitas vezes seus defensores não percebem que o discurso que encampam inviabiliza a própria ação da escola como principal agente de letramento da sociedade, dado que, no limite, a persecução por esse prazer exime o professor de pensar em objetivos claros acerca do progresso leitor de seus alunos e alunas e transforma quase em heresia o planejamento de atividades sistemáticas em torno do texto literário, sobretudo se estas se dão a partir da leitura obrigatória de uma obra. Proliferam, assim, as técnicas e estratégias de promoção (ou animação) de leitura, que, como bem observa Bajour (2012), espetacularizam o ato de ler, ficando apenas nas bordas do enfrentamento necessário e efetivamente transformador do texto literário em si.

A difusão da ideia do estímulo à leitura como uma atividade sempre agradável escamoteia questões muito complexas acerca da formação do leitor. Além da demonização da intervenção docente - que compromete um trabalho consciente e fundamentado de leitura -, não se leva em consideração $o$ fato de que a construção de preferências e hábitos de leitura está ancorada no contexto sócio-histórico dos indivíduos: todos estamos inseridos em comunidades culturais que compartilham interesses, pontos de vista e modos de ler. Os fenômenos geracionais como a série Vagalume e a saga de Harry Potter deixam bastante claro o papel das instituições sociais (escola e mercado, nestes casos) na formação do gosto. É necessário que nos perguntemos, ainda, se não estamos tomando entretenimento por fruição estética e se não estamos ignorando outras formas de prazer que não o da gratificação imediata. Interesse também se cria e se educa: não é algo peremptoriamente dado de antemão. Além disso, o elogio aos prazeres da leitura é especialmente nocivo em contextos de repetência, defasagem idade/série e dificuldades de aprendizagem. Como convencer alguém de que "ler é legal" se o enfrentamento do texto o coloca em posição de desigualdade frente aos outros colegas? Se ler, para ele, é difícil? (E costumamos não gostar do que não entendemos, é claro). Se a leitura, fora do ambiente escolar, não é dotada de valor em sua família e em sua comunidade?

$\mathrm{Na}$ base da adoção acrítica do discurso de prazer de ler está, portanto, uma confusão entre a leitura literária como prática social e a leitura literária com prática escolar. Ainda que evidentemente seja 
objetivo da escola que alunos e alunas se apropriem da leitura literária e façam dela uma prática social, não se lê na escola como se lê fora dela. Entramos, assim, nas brenhas polêmicas da escolarização da leitura literária, cuja acepção pejorativa é problematizada por Magda Soares (2001). Segundo a autora, não é possível (nem desejável) desescolarizar a leitura literária, sob pena de se anular a própria função social da escola:

(...) a leitura é sempre avaliada, por mais que se mascarem também as formas de avaliação - que se dê uma prova, que se peça preenchimento de ficha, que se promova trabalho de grupo, seminário, júri simulado, enfim, que se use seja qual for a estratégia, das muitas que a bibliografia de uma pedagogia renovadora vem sugerindo, sempre a leitura feita terá que ser demonstrada, comprovada, porque a situação é escolar, e é da essência da escola avaliar (o simples fato de se estar sempre discutindo que é preciso não avaliar explicitamente, de se criarem estratégias as mais engenhosas para verificar se a leitura foi feita, e bem feita, evidencia como a leitura é escolarizada). Lembre-se de que, fora da escola, nunca temos de demonstrar, comprovar que lemos, e que lemos bem, um livro. (SOARES, 2001, p. 24)

É compreensível que a noção de desescolarização tenha surgido como uma forma de questionar as práticas monológicas e prescritivas de leitura literária em ambiente escolar, mas a contrapartida não pode encorajar a manutenção de falsas oposições que negam à escola ser o espaço também da experimentação prazerosa e da construção de saberes inauditos. Negar o papel da literatura como uma forma de conhecimento muito peculiar (sobre si, sobre o outro, sobre o mundo, sobre a linguagem) é também negar a potência política do exercício de um direito que muitas vezes só existe via escola, especialmente para aqueles não vindos de meios letrados. E não basta oferecer-lhes livros acompanhados de um discurso bem intencionado quando sua experiência prévia não inclui relações afetivas com a leitura. Se questionamos ingenuamente a impossibilidade do trabalho sistemático e pedagogicamente fundamentado com 0 texto literário e, consequentemente, a impossibilidade de avaliar a leitura literária na escola, devemos ter clareza de que essa é uma atitude cujas consequências negativas atingem sobremaneira aqueles que dependem da escola para ter acesso à literatura e a tudo que isso significa em termos de desenvolvimento da capacidade simbólica, de percepção da relação entre forma e efeito, de exercício do imaginário, de progresso no uso da inferência e da associação, de construção identitária, de alargamento do horizonte de expectativas. Como se vê, não tem nada de anódino na prática da leitura literária em sala de aula, desde que, como atentou Magda Soares (2001), a escolarização se dê em uma chave produtiva e adequada às especificidades do texto literário.

Concordamos, pois, com Colomer (2007), para quem 0 aluno é um leitor em situação de aprendizagem e o professor um leitor experimentado que guiará o primeiro na construção de itinerários próprios de leitura, em confronto ou em diálogo com suas experiências prévias. Ao docente cabe planejar o desenvolvimento de competências leitoras, sem esquecer que a subjetividade é uma necessidade funcional da leitura do texto literário: a leitura não se reduz à cognição e se enraíza na experiência do sujeito (ROUXEL, 2012). Lemos com nossas paixões, frustrações, ideologias, crenças, experiências e memórias; todo o processamento da leitura passa obrigatoriamente pela forma como cada indivíduo recria o texto mentalmente à luz de sua subjetividade, confirmando ou reformulando seu horizonte de expectativas a partir do projeto de dizer do texto. Em outras palavras, o leitor reconfigura o texto, mas este também transforma o leitor. É a construção e reelaboração identitária que está em jogo, para além do treinamento mecânico de estratégias de leitura.

Assim, torna-se necessário encontrar uma via conciliadora para conjugar participação e distanciamento em sala de aula, ou seja, para que se equilibrem os direitos do leitor e os direitos do texto (TAUVERON, 2013) de forma a dotar alunos e alunas de recursos para se engajarem de modo mais produtivo no processo de construção dos sentidos. Propomos para isso o acolhimento de suas concretizações singulares a partir da adoção de instrumentos pedagógicos de registro escrito da 
recepção subjetiva, os quais permitem que "atitudes e reações se manifestem enquanto fatores que condicionam a apreensão do texto". (ISER, 1996, p. 7) Para os professores, esses registros se tornam ferramentas valiosas de acompanhamento dos progressos dos alunos e alunas, tanto do ponto de vista das competências quanto das atitudes para com a leitura. Para os leitores em formação, o ato de manter registros escritos sobre o que leem favorece a tomada de consciência sobre como se processa a leitura, desenvolve o automonitoramento de suas dificuldades e os ajuda a criar responsabilidade pelo próprio aprendizado, além colaborar para o estabelecimento de relação afetiva com a leitura por conta da natureza dos registros, que primam por uma orientação mais livre em relação aos tradicionais protocolos de leitura escolar. Neste caso, as impressões pessoais são legitimadas como pontos de partida para o trabalho de construção coletiva de sentido.

É na socialização das impressões pessoais de leitura que se aprofunda o trabalho com o texto literário. Falar sobre um texto é voltar a lê-lo; portanto, transformar a aula em uma "conversa literária" (BAJOUR, 2012) cria uma situação de comunicação autêntica que expande as redes dialógicas instauradas na relação texto-leitor: colegas, professor e outros textos entram em diálogo para negociar sentidos e construir uma ponte entre o individual e o coletivo; entre o leitor singular e a comunidade interpretativa a que pertence - já que as práticas sociais de leitura pressupõem que a recepção individual guarda ressonâncias da inscrição do sujeito em círculos de pertencimento culturais, portadores de protocolos específicos de validação das obras.

Teresa Colomer (2007) ressalta que o compartilhamento de leituras está na base da permanência dos hábitos leitores e da criação de laços afetivos com a leitura antes mesmo da escolarização. Torna-se, portanto, um fator nada desprezível na construção de itinerários leitores posteriores, dado que marca uma diferença significativa no ponto de partida dos indivíduos. Por isso, fazer da conversa literária uma prática na escola significa adotar uma postura política em relação à formação de leitores: é compreender que a partilha intelectual e afetiva serve de andaime para a construção de sentidos, especialmente para aqueles que apresentam dificuldades de compressão; incentiva o prazer de ler e discutir sobre as leituras; cria um círculo de referências comuns entre os interlocutores. O compartilhamento também desloca o papel de autoridade do professor, que não detém mais a prerrogativa da leitura única e "correta". Há, portanto, uma mudança de postura pedagógica, que se move do polo da repetição para o polo da criação e que exige do professor uma abertura maior ao imprevisto e à surpresa.

No interior da comunidade de leitores que se instaura na sala de aula, alunos e alunas formam gosto a partir de diferentes pontos de vista; aprendem na troca uns com os outros a fazer associações, inferências; a identificar pontos de resistência do texto; a formular e reformular hipóteses; a estabelecer relação entre forma e sentido; a perceber as camadas de significação do texto; a fazer avançarem as competências, tornando visíveis seus modos de ler. Os colegas passam a ter um papel regulador (ao refutarem, assentirem, argumentarem, autorizarem), mas também estimulador de uma postura de participação no processo de leitura e de acolhimento da alteridade:

A democracia da palavra compartilhada implica (...) o encontro intersubjetivo de vontades que aceitem o outro em sua diferença e estejam dispostas a enriquecer a vida, a leitura e a própria visão de mundo com essa diferença, mesmo que não concorde com ela. Construir significados com outro sem precisar concluí-los é condição fundamental da escuta, e isso supõe a consciência de que a construção de sentidos nunca é um ato meramente individual. (BAJOUR, 2012, p. 25)

A interação amplifica as ressonâncias do texto literário na individualidade, prolongando seus efeitos de deslocamento existencial e construção identitária. Registro individual e compartilhamento, pois, aliam objetivos de aprendizagem a investimento subjetivo e podem (re) conciliar alunos e alunas em dificuldades com a leitura, tanto pelas oportunidades de elaboração metacognitiva sobre o processamento de leitura quanto pela recepção de impressões em um 
ambiente favorável à troca intersubjetiva, como vêm apontando recentes estudos no mundo francófono (AHR e JOOLE, 2013).

O estudo de caso que será analisado a seguir pretende demonstrar a produtividade da prática pedagógica citada. Acompanharemos o percurso de um aluno repetente do sexto ano do ensino fundamental de uma instituição federal de educação básica ao longo de 2016 e 2017 por meio de registros de sua recepção subjetiva das obras literárias indicadas para compartilhamento em sala de aula. No primeiro ano, o aluno $\mathrm{W}$. registrou em diários duas das três leituras indicadas, sendo que um desses registros foi entregue incompleto; no segundo ano, W. registrou as três leituras em diários de forma integral, além de ter escrito duas autobiografias de leitor (no início e no fim do ano letivo) e quatro correspondências literárias. A tabela 1 organiza a linha do tempo das atividades.

\section{Tabela 1}

\begin{tabular}{|c|c|c|c|}
\hline Período & Tarefa & Obra & Realização \\
\hline $\begin{array}{l}1^{0} \\
\text { trimestre } \\
2016\end{array}$ & $\begin{array}{l}\text { Diário de } \\
\text { leitura } 1\end{array}$ & $\begin{array}{l}\text { O chinês } \\
\text { americano } \\
\text { (Gene Luen } \\
\text { Yang) }\end{array}$ & Não \\
\hline $\begin{array}{l}2^{\circ} \\
\text { trimestre } \\
2016\end{array}$ & $\begin{array}{ll}\text { Diário de } \\
\text { leitura } 2\end{array}$ & 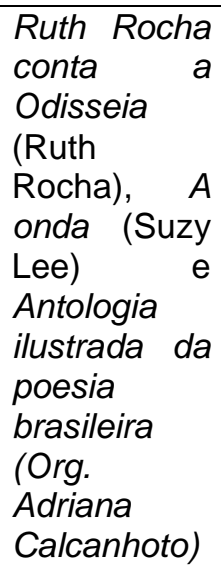 & Incompleta \\
\hline $\begin{array}{l}3^{\circ} \\
\text { trimestre } \\
2016\end{array}$ & $\begin{array}{ll}\text { Diário de } \\
\text { leitura } 3\end{array}$ & $\begin{array}{l}\text { Comandante } \\
\text { Hussi (Jorge } \\
\text { Araújo) e } \\
\text { Antologia } \\
\text { ilustrada da } \\
\text { poesia } \\
\text { brasileira } \\
\text { (Org. } \\
\text { Adriana } \\
\text { Calcanhoto) }\end{array}$ & Sim \\
\hline $\begin{array}{l}1^{0} \\
\text { trimestre }\end{array}$ & $\begin{array}{l}\text { Autobiografia } \\
\text { de leitor } 1\end{array}$ & Livre & Sim \\
\hline
\end{tabular}

\begin{tabular}{|c|c|c|c|}
\hline 2017 & & & \\
\hline $\begin{array}{l}1^{\circ} \\
\text { trimestre } \\
2017\end{array}$ & $\begin{array}{ll}\text { Diário de } \\
\text { leitura } 4\end{array}$ & $\begin{array}{l}\text { A invenção } \\
\text { de Hugo } \\
\text { Cabret } \\
\text { (Brian } \\
\text { Selznick) e } \\
\text { Santuário } \\
\text { (Will Eisner) }\end{array}$ & Sim \\
\hline $\begin{array}{l}2^{0} \\
\text { trimestre } \\
2017\end{array}$ & $\begin{array}{ll}\text { Diário de } \\
\text { leitura } 5\end{array}$ & $\begin{array}{l}\text { Aqualtune e } \\
\text { as histórias } \\
\text { da África } \\
\text { (Ana } \\
\text { Cristina } \\
\text { Massa) }\end{array}$ & Sim \\
\hline $\begin{array}{l}3^{\circ} \\
\text { trimestre } \\
2017\end{array}$ & $\begin{array}{ll}\text { Diário de } \\
\text { leitura } 6\end{array}$ & $\begin{array}{l}\text { Uma maré } \\
\text { de desejos } \\
\text { (Georgina } \\
\text { Martins) e } \\
\text { Terra dos } \\
\text { meninos } \\
\text { pelados } \\
\text { (Graciliano } \\
\text { Ramos) }\end{array}$ & Sim \\
\hline $\begin{array}{l}3^{\circ} \\
\text { trimestre } \\
2017\end{array}$ & $\begin{array}{l}\text { Cartas } \\
\text { literárias }\end{array}$ & $\begin{array}{l}\text { A bolsa } \\
\text { amarela } \\
\text { (Lygia } \\
\text { Bojunga) }\end{array}$ & Sim \\
\hline $\begin{array}{l}3^{\circ} \\
\text { trimestre } \\
2017\end{array}$ & $\begin{array}{l}\text { Autobiografia } \\
\text { de leitor } 2\end{array}$ & Livre & Sim \\
\hline
\end{tabular}

Fica visível já na quantidade de tarefas realizadas nos dos dois anos que houve uma mudança no engajamento do aluno: ele começa o ano de 2016 sem fazer os registros pessoais da leitura compartilhada e termina 2017 não só com todas as tarefas realizadas como com textos mais desenvolvidos e mais coesos, como teremos a oportunidade de verificar.

Para cada um desses 9 registros, analisamos alguns critérios relacionados à progressão das competências e às atitudes para com a leitura, usando como base as reflexões de Tauveron (2005), como pode ser visto na tabela 2 . 
Tabela 1

\begin{tabular}{|c|c|c|c|}
\hline $\begin{array}{r}\text { Critérios para avalia } \\
\text { afeti }\end{array}$ & $\begin{array}{l}\text { a apr } \\
\text { da le }\end{array}$ & $\begin{array}{l}\text { urãa } \\
\text { ura }\end{array}$ & ctual e \\
\hline O aluno... & Sim & $\begin{array}{l}\text { Um } \\
\text { pouco }\end{array}$ & $\begin{array}{l}\text { Ainda } \\
\text { não }\end{array}$ \\
\hline ... faz inferências. & & & \\
\hline $\begin{array}{l}\text {... levanta e reformula } \\
\text { hipóteses. }\end{array}$ & & & \\
\hline $\begin{array}{l}\ldots \text { relaciona o que lê } \\
\text { com outros textos. }\end{array}$ & & & \\
\hline $\begin{array}{l}\ldots \text { relaciona o que lê } \\
\text { com sua experiência. }\end{array}$ & & & \\
\hline $\begin{array}{l}\text {... demonstra reações } \\
\text { afetiva ao que lê. }\end{array}$ & & & \\
\hline $\begin{array}{l}\text {... demonstra atenção às } \\
\text { pistas textuais. }\end{array}$ & & & \\
\hline $\begin{array}{l}\text {... demonstra atenção às } \\
\text { pistas paratextuais. }\end{array}$ & & & \\
\hline $\begin{array}{l}\ldots \text { desenvolve suas } \\
\text { ideias, justificando-as. }\end{array}$ & & & \\
\hline $\begin{array}{l}\ldots \text { faz perguntas, } \\
\text { questiona o texto, expõe } \\
\text { dúvidas. }\end{array}$ & & & \\
\hline $\begin{array}{lr}\text {...busca } & \text { alternativas } \\
\text { para } & \text { superar } \\
\text { dificuldades. } & \end{array}$ & & & \\
\hline $\begin{array}{l}\ldots \text { integra as } \\
\text { contribuições dos } \\
\text { colegas ao seu texto. }\end{array}$ & & & \\
\hline $\begin{array}{l}\text {...reavalia suas } \\
\text { impressões e opiniões. }\end{array}$ & & & \\
\hline ...reficcionaliza o texto. & & & \\
\hline $\begin{array}{l}\text {.. demonstra } \\
\text { identificação } \\
\text { desidentificação. }\end{array}$ & & & \\
\hline ... faz leitura simbólica. & & & \\
\hline
\end{tabular}

O trecho abaixo é ilustrativo de como os registros iniciais de $W$. eram frágeis do ponto de vista da escrita e careciam de elementos reveladores do processamento da leitura: $>\quad$ Achei a narrativa dela é bem escrita e muito legal, as imagens é chamativa para mostrar para o leitor ver que o livro é interessante e muito bem feita e muito bonita mas a maioria das páginas é em preto e branco, muito interessante, porque é muito bem narrada e bem fácil de entender, não, lembro eu queria bater no mar porque eu tomei caixote, sim, porque eu gosto de nadar, nada.

$>\quad$ Muito bons, rima bem e etc, do primeiro, porque tem mais rimas a terceira, porque quase não tem rima.

> A onda explica que o mar é um personagem na Odisseia.' (Diário de leitura 2)

W. responde as perguntas do roteiro como um questionário e tem dificuldades de utilizá-lo como um guia para a produção textual. O resultado é um "texto" fragmentado, separado em tópicos nada compreensíveis isoladamente, com inúmeros problemas de coesão (como o mau uso da referenciação, passando por problemas estruturais de construção de período) e bem pouco desenvolvido do ponto de vista de suas impressões pessoais. Os adjetivos empregados são vagos e não revelam apropriação subjetiva real da leitura ("legal", "interessante", "bem feita"); há dificuldades de argumentação (W. não consegue ater-se às pistas textuais para fundamentar suas ideias e usa argumentos tautológicos) e quase não há aproveitamento das contribuições dos colegas durante o compartilhamento (aparece apenas uma breve referência aos efeitos de sentido dos recursos empregados na capa). Consta no registro uma vaga menção a uma experiência pessoal, mas sem reverberação efetiva na construção de sentidos do texto. O automonitoramento também não ocorre. W., que tem dificuldades de compreensão leitora, afirma que a narrativa é fácil, mas vários colegas apontaram na discussão que os paratextos informativos que dividiam espaço com o texto ficcional atrapalhavam a leitura. Além disso, ele faz uma afirmação confusa sobre a relação entre $A$ onda e Ruth Rocha conta a Odisseia, que revela uma má compreensão do fenômeno da intertextualidade, sem que a discussão em sala tenha conseguido resolver. (W. entende que

\footnotetext{
${ }^{1}$ Houve correção apenas da ortografia para facilitar a leitura. Não alteramos a pontuação nem a coesão dos registros.
} 
A onda foi escrita em diálogo proposital com Odisseia)

No diário seguinte, W. consegue cumprir todas as etapas, mas mantém a maioria das dificuldades. 0 texto ainda é muito fragmentado e pouco desenvolvido, a argumentação não progride e o automonitoramento não existe. Entretanto, ele começa a interferir mais subjetivamente no texto, ainda que de forma esparsa e sem explicitar a relação com o texto lido:

Sobre minha família como sou descendente de africano meu tataravô veio pra cá em busca de emprego aí conheceu minha tataravó e teve um filho que é meu avô estava desempregado e minha avó esta[va] no segundo grau ainda aí ela teve que largar os estudos eles t[i]veram que morar em um barraco aí eles passavam fome etc. (Diário de leitura 3)

É possível perceber uma atenção nascente para as pistas textuais e seus efeitos de sentido “(...) gostei da intuição do autor de um desenho feio de um passado feio porém essa ilustração são bem realista expressam sentimento." (Diário e leitura 3) - e uma incipiente leitura simbólica - "Uma hora Hussi era adulto outra hora ele era uma criança porque quando estava na guerra ele era adulto para levar comida armas e etc mas a criança estava dentro dele e quando ele estava perto da bicicleta a criança saía de dentro dele." (Diário de leitura 3) Diferentemente do diário anterior, aqui W. se arrisca em uma atividade de reficcionalização do texto ao mudar o desfecho:

A guerra terminou, o Trovão virou do bem e o meu país ficou em paz depois ele foi se reconstruindo a gente não passou mais fome agora não sou mais criança sou comandante ninguém mais vive na pobreza todos comem carne todos os dias essa guerra serviu para nós nos entendermos e respeitar uns aos outros, e saber que todo mundo é igual. (Diário de leitura 3)

Segundo Langlade (2008), a atividade ficcionalizante do leitor - ou seja, a resposta do seu imaginário às solicitações da obra - é o índice mais importante de que há engajamento subjetivo no processo de leitura literária. A participação do imaginário do leitor pode se dar em diferentes graus, desde a instauração da coerência mínima da obra (estabelecimento de relações causais, visualização de cenas e ambientes, julgamento moral dos personagens) até a alteração do texto por meio de supressões, transformações e acréscimos que, quando estimulados por acompanhamento didático, aumentam as possibilidades de engajamento do leitor na leitura.

No exemplo acima, W. alterou o desfecho da obra em virtude de um incômodo (sinalizado em outros momentos do diário) com a atmosfera ora violenta, ora melancólica da narrativa. É interessante que W. tenha se colocado no lugar de Hussi (não havia essa instrução, foi uma escolha do aluno), radicalizando a vivência da alteridade que se processa durante a leitura. Chama a atenção ainda a referência a "comer carne todos os dias", retomando uma descrição da primeira página do livro e revelando que o ponto de fixação de $\mathrm{W}$. neste trecho sinaliza para aquilo que moveu sua sensibilidade. Se lembrarmos que o aluno descreveu a vida dura dos avós descendentes de africanos escravizados no Brasil em outro momento do diário, ficam mais evidentes os movimentos da subjetividade em marcha. Por fim, embora o desfecho da obra não seja muito diferente do que registrou W., aqui há uma ênfase nos aspectos positivos não elencados na narrativa (parece haver uma necessidade de deixar o desfecho mais "amarrado" e explícito) e o preenchimento de um vazio incômodo: Trovão, o antagonista, cujo destino não é revelado no enredo, torna-se um mocinho. Está explícita aqui uma expectativa possivelmente criada por leituras prévias: a dos desfechos apaziguadores e indubitavelmente conclusivos.

No primeiro diário de 2017, é notável a mudança na estrutura do texto: de trechos fragmentados, com problemas de coerência acarretados por falta de coesão, para um relato de fato, que inclusive incorpora elementos do compartilhamento de leitura - o que permite ainda que W. comece a atentar para os índices formais do texto, monitorando sua leitura, e para o estabelecimento de relações intertextuais: "Meus amigos falaram de livros que eu não havia imaginado sendo que alguns eu já li como: $O$ chinês americano, 
Comandante Hussi e entre outros, falaram das imagens da capa que eu não percebi que eram tristes."/ "Um ponto que eu buguei [foi] na hora que falaram que o livro é preto e branco por causa que ele é para ler como se fosse uma tela de cinema." (Diário de leitura 4) A leitura simbólica também avançou, bem como a explicitação da projeção subjetiva:

No final fiquei muito emocionado [emoji chorando] porque ele queria uma coisa $e$ ganhou uma coisa mais importante que tudo nessa vida que foi a família ele achava que nada na vida dele seria mais importante que o autômato ele achava que o autômato era a chave da vida (o que ia abrir a porta da vida dele) porém o amor de família é muito maior que uma invenção. (Diário de leitura 4)

O mecanismo da identificação, da explicitação de uma reminiscência afetiva, aparece também de forma mais orgânica, integrada à leitura global que W. faz da narrativa, diferentemente da menção que ele fez à história de sua ascendência africana no diário anterior, cujas relações com a narrativa ficcional ficaram implícitas:

Para mim Hugo queria ser invisível porque ele não tinha família, amigos e não tinha felicidade, uma vez que tentei ser invisível foi quando repeti de ano eu tinha vergonha porque vi meus amigos rindo se divertindo do ano passado e só eu lá com um monte de pequeninos de cabeça baixa pensando (...).(Diário de leitura 4)

No segundo diário de 2017, o salto é ainda maior. A primeira evidência é a própria extensão do texto escrito: o diário começou como fragmentos, se tornou um texto curto (de um parágrafo cada etapa) e agora é um relato longo (uma página ou mais cada etapa). Tauveron (2005) também observou o aumento gradativo do volume do texto escrito nos estudantes com dificuldade de aprendizagem que investigou (além da maior participação deles nos debates). Isso demonstra, segundo a autora, que a consideração da palavra escrita e falada desses alunos e alunas os torna mais seguros, estimulados e condescendentes em relação aos erros cometidos, já que se sentem parte de uma comunidade que se arrisca o tempo todo sem ser censurada por isso. Acrescentemos, ainda, que os feedbacks orais nas sessões de compartilhamento e, sobretudo, os escritos nos diários (que procuram ser o diálogo de um outro leitor, e não uma voz "corretora" e sancionadora de interpretações) são fatores preponderantes para a mudança de postura leitora. Importa salientar que parece haver uma relação estreita entre o tamanho do texto e a leitura manifesta por escrito: quanto mais abundante é o texto, não só o processamento de leitura do aluno se torna mais acessível como também o envolvimento afetivo com o lido se mostra mais intenso. Em outras palavras, quanto maior o impacto pessoal da leitura, maior fica o texto. Além disso, conforme as competências avançam (e parece claro que compreensão e fruição não estão dissociadas), vão desaparecendo os resumos e referências ao conteúdo temático da obra para dar lugar a um trabalho verdadeiramente crítico de leitura. Os dois últimos diários de W. mostram justamente isso:

Eu achei a capa bem chamativa tem uma mulher negra uma lança parece que ela vai pra guerra acredito que seja para ela se libertar a orelha é preta eu [acho] que é pra demonstrar tristeza, a cor da pele e sujo. Aparenta ser muito triste eu estou curioso pra ler o livro está aparentando muito que eu vou chorar de tristeza e das conquistas que eu acho que vai ter eu acho que a principal personagem vai ser essa mulher na capa essa mulher está com roupas muito coloridas que eu acho que são pra representar a nossa cultura (...). Estou bastante curioso pra ler o livro estou quase lendo mas tenho que segurar [emoji triste - grifos nossos] (Diário de leitura 5)

Neste trecho, chama a atenção a busca consciente por coerência. Percebemos o olhar atento aos recursos gráficos como geradores de hipóteses de leitura, marcadas inclusive verbalmente (colocamos em negrito) - algo que estava ausente nos primeiros diários e é certamente resultado do compartilhamento. Há também evidente transferência de conhecimento construído nas leituras anteriores: o fato de a cor preta ser um elemento que constrói uma atmosfera de tristeza ou colabora para dar a impressão de envelhecimento do papel (é o que ele quis dizer com "sujo"). W. também cria expectativas com base em seu conhecimento prévio sobre narrativas ao mencionar as "conquistas" (complicações e reviravoltas) e a personagem principal. Ele antecipa também o efeito da obra a partir das pistas gráficas e emprega um recurso para 
sinalizar suas reações emotivas que se torna recorrente em seu diário: o uso de desenhos representando os emojis das interações virtuais. Além disso, é importante sublinhar a internalização do processo de escrita do diário e a compreensão do processo pedagógico: $\mathrm{W}$. sente vontade de continuar lendo, mas sabe que isso afeta a rotina de trabalho e, consequentemente, a maneira como se dá 0 compartilhamento.

No excerto abaixo, é interessante observar, além da crescente atenção à forma, a também crescente expressão de dúvidas, antes ausente do diário, e que se revela ora sobre o dito, ora sobre 0 não dito e, como no exemplo a seguir, sobre o alcance simbólico dos recursos empregados. $\mathrm{Na}$ verdade, este é um caso revelador da postura de "suspeita" construída coletivamente acerca da manipulação formal, que tornou sua leitura vigilante:

Eu já abri o livro e tive uma dúvida porque numas cores tão bonitas e chamativas com ilustrações tão belas tem uma mancha ou uma sombra eu não sei explicar mas essa é uma situação inicial, vamos ver o que tem nisso. Na página 11 parece que ela sofria porque eu acho que ela dormia numa cama dura por ter falado da cama vazia também acho que a avó dela morreu porque fala no texto que os avós viveram não vive[m]. (Diário de leitura 5)

Notemos como isso modificou a relação com o desenvolvimento do enredo: W. passa a perceber que a leitura não é apenas uma superfície, mas um volume a ser lido por camadas e, portanto, como ressalta Jouve (2002), certas conexões não podem ser percebidas na linearidade imediata. A postura paciente pela busca de coerência contrasta com necessidade demonstrada no Diário 2 de arrematar um desfecho percebido como vago. W. agora se abre à imprecisão e aos pontos de indeterminação do texto. Há ainda mostras de inferências motivadas por dados textuais (os adjetivos "dura" e "vazia", além do tempo verbal) - que são tomados pelo aluno como evidências do seu raciocínio - e o uso consistente e operacional da nomenclatura aprendida em sala em outro momento ("situação inicial"), como acontece também no exemplo abaixo:

Lendo o segundo parágrafo da página 61 não entendi o que significa balbuciava. Eu senti que ela teve uma conexão direta como leitor ela fala "O que vocês fariam no meu lugar". Agora vi que ela falava com amigos dela que são Maria e Kafil. (...) Teve uma quebra de expectativa quando Kafil vai dar um beijo em Alice pelo texto parece que eles vão dar um beijo na boca só que de repente foi na bochecha. Eles parecem se gostar um do outro. Agora que percebi que cada capítulo tem um número através de ilustrações. $O$ texto é bem informal e é muito da linguagem de hoje porque fala da palavra "frenético". Gostei bastante desse capítulo foi bem legal principalmente os rolos dos beijos. Kkkkkkkk [emoji chorando de rir] (Diário de leitura 5)

W. se mostra claramente mais instrumentalizado para ler a narrativa de forma vigilante ao transferir coerentemente para esta nova leitura noções trabalhadas em contextos prévios: a noção de quebra de expectativa e os recursos de aproximação e envolvimento da obra com o leitor (o diálogo direto com o interlocutor fictício - neste caso percebido como ambíguo por W. - e o registro linguístico informal). Outra questão relevante que aparece neste e no trecho a seguir é a mudança de dicção do relato de W., que cada vez mais se assemelha a uma espécie de fluxo de consciência, de representação de seus movimentos mentais durante a leitura. No trecho acima, isso fica marcado pelo "agora"; no trecho abaixo, pelas interjeições, pelo alongamento da vogal (também sinais de seu crescente envolvimento afetivo) e pela própria menção ao processo de escrita como recurso falho na apreensão absoluta do que lhe acontece durante a leitura:

O capítulo 6 já começa com imagens ou ilustrações de baú sendo aberto parece que é o desfecho do porquê, tipo a solução do livro. Eeeeeee! É exatamente [o] que eu deduzi é o desfecho mas estou feliz e triste ao mesmo tempo porque está terminando...(...) Agora Alice ou Aqualtune entrou totalmente na história do nome dela e está se aceitando mais. Nooooossaaaaaa meu Deus o Guilherme e a Maria assumiram o namoro deles, não anotei muito porque fiquei com muita emoção (...) Ah e vou dar uma moral "se aceite do jeito que você [é], não se importe com sua cor, com seu cabelo e com suas características. Se olhe no espelho e simplesmente aceite". Tem uma música muito maneira que se chama "Bate a poeira" é muito legal e fala de tudo isso. (Diário de leitura 5)

Também chama a atenção a satisfação com o jogo de levantamento e verificação de hipóteses, a 
necessidade de "moralizar" o texto a partir se sua leitura global (resposta estimulada pela própria narrativa) e, finalmente, o estabelecimento de relação entre textos para além da rede intertextual construída na sala de aula, à qual W. recorre frequentemente:

Oi diário, hoje estou aqui pra relatar como é o livro sem ler apenas observando. Na primeira capa as cores são chamativas e pelo título parece que a menina da capa relata no livro os sentimentos dela que aparenta ser um monte de desejos, eu gostei que o livro já coloca uma coisa que o mar pode ser representado e pela expressão facial da menina parece que ela está gostando do menino que está atrás dela. Caramba acertei na mosca, atrás do livro fala que a garota que se chama Sergiana, gosta do garoto que se chama Luciano. Eu gostei da imagem da quarta capa é uma continuação da frente igual ao "chinês americano". Folheado o livro acho que podia ter mais imagens para te prender no livro eu estou interessado em ler para tirar curiosidades. (Diário de leitura 6)

Além de o trecho exemplificar várias questões já levantadas sobre o progresso de W., ele revela uma nova evidência da sua apropriação afetiva da leitura literária e do diário como testemunha desta nova relação íntima: o uso do vocativo em todos os registros do último diário. Essa apropriação aparece ainda no maior cuidado e capricho com que W. ilustra seu diário, personalizando-o a partir de reficcionalizações gráficas: desenhos de cenários e reformulação da capa da obra.

É possível perceber, pelo acompanhamento cronológico dos registros, que houve um avanço considerável na capacidade de emitir juízos de valor (acompanhada do recuo da paráfrase) e o desenvolvimento de uma atitude reativa aos recursos textuais e paratextuais, evidenciando o diálogo entre o efeito, pré-programado pela narrativa, e a recepção, concretizada pelo leitor (ISER, 1996). Entretanto, é preciso que se reitere que o progresso observado só foi possível em virtude do esforço de se trabalhar a leitura literária como uma experiência pessoal a ser partilhada. Isso é importante para entender a falta de engajamento inicial de W. nas tarefas escolares envolvendo a leitura, revelada por sua autobiografia de leitor escrita no início de 2017:

(...) Quando eu era menor eu me achava muito né, aí falava que não gostava dos livros, mas no fundo eu adorava, eu só não gostava que meus amigos mais velhos falavam que eram de criança aí eu me trancava no quarto e ficava lendo para ninguém me ver lendo./ Quando cresci fiquei com menos vontade de ler não gostava de livros e nem de gibis, aí foi quando eu me fechei no quinto ano ninguém gostava de mim porque eu era fechado e quando as pessoas falavam comigo eu dava um fora. (Autobiografia de leitor 1)

A pressão da comunidade imediata, que parece não legitimar a leitura como fonte de lazer ou conhecimento, contribuiu para que W. se afastasse dos livros. Talvez a ideia de que a leitura "é coisa de criança" se deva à identificação do livro com o momento da alfabetização apenas, o que leva os amigos de W. a desvalorizar a leitura como uma prática social. É interessante notar a relação que ele faz entre o fato de não ler e ter se tornado "fechado". Isso fica mais claro na continuação de seu relato:

(...) aí preferi vir para o turno da manhã e encontrei uma professora e leitora de mãos cheias e acabei me abrindo, lendo e até participando (...) eu voltei a ler a me interagir. (...) Hoje em dia sou muito aberto interajo muito e gosto de ler a bíblia e os livros isso transformou minha vida, gosto muito de ficção científica, histórias de guerras e muitas histórias em quadrinho. (Autobiografia de leitor 1)

A diferença que $W$. faz implicitamente entre "professora" e "leitora" é digna de nota. Ele parece querer dizer que houve uma mudança de status em virtude da postura docente em sala de aula, que visava ao diálogo e não à exposição de conteúdo. É curioso que ele use os dois substantivos, como se quisesse sublinhar que nem sempre as atividades do professor sejam assimiláveis às do leitor. Também é importante destacar que ele reassocia a leitura à sua personalidade. W. não só afirma explicitamente que houve uma transformação pessoal via leitura literária, ou seja, que reelaborou sua identidade, como ainda atesta que se apropriou da leitura e a tomou como prática social ao citar os gêneros que passou a ler. Esse aspecto aparece em outros momentos, como quando W. recomenda Comandante Hussi porque "ele mexe lá no fundo do caráter da pessoa" (Autobiografia de leitor 1). Não é por acaso que seja esta uma das obras citadas como mais importantes em sua autobiografia de leitor: 
Um livro que eu gostei muito foi o "comandante Hussi" ele é um garoto mais ou menos da minha idade que lutou pela sua vida de criança e sua vida de adulto na GuinéBissau um país de muitas guerras e mortes e eu me identifiquei muito porque ele é um jovem que luta por sua liberdade. (Autobiografia de leitor 1)

Os registros pessoais das cartas literárias sobre $A$ bolsa amarela trocadas com um colega de outra turma confirmam as mudanças operadas em W. No fim do percurso aqui delineado, é possível perceber um avanço considerável no que diz respeito ao estabelecimento espontâneo de relações intertextuais, ao automonitoramento do processo de leitura e à realização de inferências, aspectos totalmente ausentes dos primeiros registros em 2016. O objetivo da atividade era permitir que as trocas intersubjetivas pudessem auxiliar os alunos a engajarem-se mais significativamente na leitura. Por isso, o aluno W. foi pareado com um colega mais proficiente, de modo que pudesse se beneficiar de suas competências. Importa dizer ainda que essas cartas correspondem ao final do processo considerado neste trabalho, após dois anos do estabelecimento de uma rotina de registro e discussão. Além disso, as orientações para o registro foram mais livres que as do diário, o que nos leva a pensar em uma efetiva apropriação pessoal desse instrumento de escrita. Os trechos abaixo são bastante significativos a esse respeito:

Agora com certeza o livro vai fazer igual ao Aqualtune me joga na história e depois me puxa. Ele deve falar o presente [desenho de um presente] que ela quer aí vou dar ou tentar dar hipóteses do porque ela pediu aquele presente aí depois ele fala algo pra me tirar da "adivinhação" e me coloca em outra e fica assim o tempo todo./ Aí já me deixa com raiva [emoji de raiva] na hora que ela ia falar o que escreveu o livro já tira você de novo pra ficar com mais dúvidas ainda, mas ela continuou a escrever, agora tomara que ela revele logo o que escreveu, eu quero matar a charada dessa história uma parte igual a Aqualtune é que quanto mais você lê mais dúvidas você fica e isso é um ponto que eu particularmente não gosto. [emojis de raiva] (Cartas literárias)

$\mathrm{Na}$ primeira parte já vi uma relação com os dois livros que a gente leu, fala dos desejos que está escrito na primeira página porque vontades e desejos são a mesma coisa (...). No livro fala que uma vontade é crescer e deixar de ser criança logo parece que a infância dela não é muito boa e sim muito ruim como a Georgina Martins do livro "Uma maré de desejos". (...) Não entendi a palavra desatou? Você entendeu? (Cartas literárias)

Aaaaa até que enfim a bolsa esvaziou e os desejos dela foram todos para fora e os romances que ela escreveu, foram todos os sentimentos revelados quase de novo chorei e o que foi engraçado foi que todos os livros desse ano eu chorei esse foi o único que consegui segurar, mas que livro é esse. (Cartas literárias)

O primeiro trecho demonstra um evidente refinamento das estratégias de leitura empregadas por $\mathrm{W}$. A relação que ele estabelece com o livro lido no trimestre anterior se dá por meio do reconhecimento de recursos narrativos semelhantes, recursos estes que inserem as obras num rol de "textos resistentes" (TAUVERON, 2005) - ou seja, textos que convocam o leitor à resolução de problemas, portanto colaboram para o desenvolvimento de competências leitoras. A conversa literária, ressalta Bajour (2012), começa já na seleção de textos convidativos à participação do leitor. O que W. faz no primeiro trecho acima é confirmar a produtividade da escolha de textos que proponham desafios aos alunos. A ideia de "jogar e puxar" referida por ele remete justamente à necessidade de desautomatização do ato de leitura para que se chegue a outras camadas de significação. Ele usa explicitamente a noção de levantamento e checagem de hipóteses e emprega os termos "adivinhação" e "charada" para dar conta do seu processamento cognitivo. Embora W. diga sentir raiva e não gostar do fato de sua leitura não ser linear, o fato é que é justamente o jogo de caça às pistas que o move e o prende ao enredo - o que fica visível na sua ansiedade pela continuidade e no seu desejo de "matar as charadas".

Neste trecho e no seguinte também é possível perceber uma maior exposição de suas dúvidas, inclusive com um pedido de ajuda para resolver o problema. Podemos notar também a explicitação de uma inferência acerca da vida da personagem que evolui para o estabelecimento de relação intertextual com o outro livro lido no trimestre. Começamos a perceber uma naturalização do ato de comparar e 
procurar conexões entre os textos, o que acaba por criar uma rede de referências pessoais e coletivas que alargam o repertório de W. e contra as quais ele poderá projetar suas novas leituras. Há também muito mais marcas de investimento afetivo que nos primeiros registros, como os já citados emprego de emojis, interjeição, alongamento de vogal e verbalização de emoções. O que percebemos no fim desse processo é que a criação de um ambiente propício à partilha sem censura à palavra do outro colabora para que se rompa com a cultura escolar do fracasso na qual vários de nossos alunos estão imersos. Eles passam a se sentir seguros e mais responsáveis por seu aprendizado quando percebem que o esforço de compreensão é coletivo. No caso de W., a obra lida serviu ainda como veículo de simbolização para sua relação fragilizada com a escola:

Já começou o capítulo com um título chato que é a volta das aulas, e também no texto fala a coisa mais "dolorante" do mundo é ir para a escola com sua bolsa leve e voltar com a bolsa mais pesada que uma pedra gigante, acontece isso por causa do conteúdo, podia não acontecer isso, seria melhor né? (Cartas literárias)

W. exprime por meio da comparação e de um saboroso neologismo seus afetos mobilizados pelo ficcional do texto. Entretanto, o ficcional do texto também é alterado por seus afetos: "Mano imagina se ela [a personagem] tivesse uma prof igual $a^{* * * *}$ pra ajudá-la a procriar a imaginação dela seria uma menina incrível muito inteligente e sábia em qualquer coisa e pra qualquer coisa [emojis sorrindo]" (Cartas literárias). O mecanismo da identificação está aqui em ação em sua forma mais poderosa. Raquel, a personagem de $A$ bolsa amarela, é tomada como símbolo da própria transformação das atitudes de W. para com o aprendizado e a leitura; ele se projeta na personagem transferindo para ela o que vê como possibilidade em si.

O estudo de caso aqui apresentado nos mostra que a adoção do registro de recepção subjetiva, acompanhado do compartilhamento, oferece aos alunos e alunas menos proficientes oportunidades de serem donos de sua própria voz, desenvolverem suas competências e assumirem o risco da interpretação.
A escrita e a discussão os ajudam a refletir sobre seu processo de leitura e por isso assumem a função de explicitação, clarificação e autoavaliação (TAUVERON, 2005). O percurso observado ao longo de dois anos nos mostra uma trajetória singular de progresso intelectual e afetivo muito reveladora do potencial pedagógico da escrita como ato de recepção leitora. Vemos, assim, concretizar-se um projeto de leitor em pelo menos quatro dimensões: textual (pelo avançar das competências), cultural (pela inserção em uma comunidade de leitores e pela construção de uma rede de referências), identitária (pela reelaboração da autoimagem de aluno e leitor) e afetiva (pela recuperação da relação de prazer com a leitura). "Singular" é uma palavra-chave aqui. Resultados parecidos foram alcançados com alguns alunos; resultados muito díspares e frustrantes com outros. Apesar das potencialidades dos instrumentos, há de se considerar que a via aberta pela subjetividade é a via do imprevisível e da constante negociação.

Os registros pessoais se tornam, pois, instrumentos valiosos para uma avaliação formativa, processual, individualizada do leitor, permitindo um acompanhamento muito mais efetivo das limitações e progressos dos alunos e alunas em suas singularidades. Pela natureza intersubjetiva desse dispositivo (assim como do compartilhamento), estabelece-se um vínculo de confiança e afeto entre aluno e professor que altera de forma significativa a relação com o aprendizado, com a leitura e com a escola, colocando em perspectiva a falsa dicotomia entre prazer de ler e escolarização.

\section{Referências}

AHR, Sylviane; JOOLE, Patrick (Orgs.). Carnet /journal de lecteur/lecture: quel usages, pour quels enjeux, de l'école à l'université? Namur: Presses universitaires, 2013.

BAJOUR, Cecilia. Ouvir nas entrelinhas: o valor da escuta nas práticas de leitura. São Paulo: Pulo do gato, 2012.

COLOMER, Teresa. Andar entre livros: a leitura literária na escola. São Paulo: Global, 2007. 
DELBRASSINE, Daniel. Découvrir La "lecture littéraire" avec des romans écrits pour la jeunesse. Namur: Presses universitaires, 2007. Collection Tactiques.

ISER, Wolfgang. $O$ ato de leitura. Tradução de Johannes Kretschmer. São Paulo: Editora 34, 1996.

JOUVE, Vincent. A leitura. São Paulo: UNESP, 2002.

LANGLADE, Gérard. Activité fictionnalisante du lecteur et dispositif de l'imaginaire. Figura, Montréal, n. 20, p. 45-65, 2008.

ROUXEL, Annie. Práticas de leitura: quais rumos para favorecer a expressão do sujeito leitor? Cadernos de Pesquisa [online]. 2012, vol.42, n.145, pp.272283.

SOARES, Magda. A escolarização da literatura infantil e juvenil. In: EVANGELISTA, Aracy Alves Matins et al. (Orgs). A escolarização da leitura literária: o jogo do livro infantil e juvenil. Belo Horizonte: Autêntica, 2001

TAUVERON, Catherine. Que veut dire évaluer la lecture littéraire? Cas d'élèves en difficulté de lecture. Revue Repères, Lyon, v.1, n. 31, p.73112, 2005.

Direitos do texto e direitos dos jovens leitores: um equilíbrio instável. In: REZENDE, Neide Luzia et al. (Orgs.) Leitura subjetiva e ensino de literatura. São Paulo: Alameda, 2013.

\section{COMO CITAR ESSE ARTIGO}

SOUZA, Raquel e. DAS (IM) POSSIBILIDADES DE AVALIAR A LEITURA LITERÁRIA NA ESCOLA: UM ESTUDO DE CASO. Signo, Santa Cruz do Sul, v. 43, n. 78, nov. 2018. ISSN 1982-2014. Disponível em: <https://online.unisc.br/seer/index.php/signo/article/view/11985>. Acesso em: https://doi.org/10.17058/signo.v43i78.11985. 